\title{
Analysis of staged treatment and some socio- hygienic and biological factors for the onset and course of gastric ulcer and duodenal ulcer
}

\author{
M.K. Tukhtaev ${ }^{1}$, N.M. Tukhtaeva ${ }^{2, *}$ \\ Samarkand State University \\ Siyab College of Public Health named after Abu Ali ibn Sino
}

\begin{abstract}
In a social-hygienic study, some factors influencing the occurrence and dynamics of the course of gastric ulcer and duodenal ulcer in 379 patients were studied. The results of the data show that the complete staged treatment (polyclinic, hospital, sanatorium) is not carried out for all patients $(24.3 \%)$ for the entire study period. In the first year of the disease, it was carried out in only $6.8 \%$ of patients. To determine the strength of the influence of some socio-hygienic and biological factors on the dynamics of the course of peptic ulcer disease, we used the method of analysis of variance. The analysis of the dynamics of gastric ulcer and duodenal ulcer with the calculation of a static assessment, which reliability is quite convincing, made it possible to conclude with maximum reliability that the dynamics of the disease, in addition to surgical treatment $45.1 \%$ (with complications in the form), is most strongly influenced by the nutrition factor $8.5 \%$... The effect of other factors is approximately the same: material housing conditions $6.6 \%$, the psychological factor $6.5 \%$ and working conditions $4.5 \%$.
\end{abstract}

The incidence of gastric ulcer and duodenal ulcer still remains one of the problems of medicine in all countries of the world, which is associated with its significant prevalence, the frequency of relapses and complications leading to temporary and permanent disability, as well as high mortality.

Clinical examination as a method of prevention in the social aspect of diseases has turned into a scientific and organizational system that includes such factors as improving the speed of work and life, preventive and curative health-improving measures, and dynamical monitoring of the state of health of the violence. Therefore, the identification of such moments in the onset of peptic ulcer disease called "risk factors" is of great scientific and practical importance [1-5]. At the same time according to the recognition of researchers, few works are devoted to the study of socio-hygienic factors of the course of peptic ulcer disease of the stomach and duodenum (including the identification of "risk factors") [6-9]

In the study of 14 polyclinics and 8 hospitals, we received data for adults in Samarkand city, as well as regional institutions - the archive of the Marriage registry office and the Statistical Office, Medical Labor Expert Commission of the city, and the Regional Trade

* Corresponding author: nargizamustafayevna82@gmail.com 
Union. In total, the study covered 26 institutions. The objects of observation were patients with gastric ulcer and duodenal ulcer - the inhabitants of Samarkand city, treated in medical institutions for three years.

We tried to study the socio-hygienic and biological factors and staged treatment for peptic ulcer disease. In a socio-hygienic study, the factors influencing the occurrence and dynamics of the course of gastric ulcer and duodenal ulcer were studied in 397 patients.

We have studied all stages (polyclinic, hospital, sanatorium) in the provision of medical care for peptic ulcer disease. The results are shown in the Table 1.

Table 1. Coverage of staged treatment of patients with peptic ulcer in the first year and for the entire study period

\begin{tabular}{|c|c|c|c|c|c|c|}
\hline \multirow{2}{*}{$\begin{array}{c}\text { Year of } \\
\text { observation }\end{array}$} & \multicolumn{2}{|c|}{ Total patients } & \multirow{2}{*}{$\begin{array}{c}\text { Passed } \\
\text { from all } \\
\text { stages }\end{array}$} & $\begin{array}{c}\text { Passed } \\
\text { stationary } \\
\text { treatment }\end{array}$ & $\begin{array}{c}\text { Passed } \\
\text { sanatorium } \\
\text { stage }\end{array}$ & $\begin{array}{c}\text { Under } \\
\text { dispensary } \\
\text { supervision }\end{array}$ \\
\cline { 2 - 3 } The 1st year & 379 & 100 & $6.8 \% \pm 1.3$ & $31.2 \% \pm 2.4$ & $3.1 \% \pm 0.9$ & $13.3 \% \pm 1.7$ \\
\hline $\begin{array}{c}\text { For the } \\
\text { entire study } \\
\text { period }\end{array}$ & 379 & 100 & $24.3 \% \pm 2.2$ & $72.1 \% \pm 2.3$ & $24.3 \% \pm 2.2$ & $45.9 \% \pm 2.6$ \\
\hline
\end{tabular}

The analysis of the data shows that not all patients receive complete staged treatment (24.3\%).

In the first year of the disease, when complete staged treatment is much more effective, it was carried out in only $6.8 \%$ of patients. Inpatient and spa treatment in most cases is carried out in the late stages of the disease, when long-term outpatient treatment does not, as a rule, give the desired effect.

Special attention should be paid to the coverage of dispensary observation, which is $45.9 \%$, and the number of those covered in the first year of the disease is low (13.3\%). More than half of the patients are not under dispensary supervision.

In our research we also studied the influence of some socio-hygienic and biological factors on the dynamics of the course of peptic ulcer disease. Among the sick people living in poor material and housing conditions, unsatisfactory dynamics were noted in $26.9 \%$ of cases, and among those living in good conditions in $6.6 \%(\mathrm{P}<0.01)$. With the deterioration of material and housing conditions, the number of patients who showed good dynamics significantly decreased from $52.6 \%$ to $11.5 \%(\mathrm{P}<0.01)$.

Comparison of the dynamics of the course of peptic ulcer disease with the nature of labor activity showed that the percentage of unsatisfactory dynamics among patients engaged in physical labor was $11.6 \%$, which is significantly $(\mathrm{P}<0.01)$ more than among patients who are engaged in mental labor $(3,6 \%)$.

In the group of working patients, in whom it was not possible to identify unfavorable factors of labor, unsatisfactory dynamics of the course of the disease were observed in only $16.2 \%$ of cases. However, in the presence of such factors (forced position of the body, overtime work, frequent business trips and night shifts), the proportion with unsatisfactory dynamics increased, reaching $41.4 \%$ of patients with good dynamics in patients exposed to three or more unfavorable labor factors; this decreased by 1.4 times (from $61.5 \%$ to $43.5 \%$ ).

Unsatisfactory dynamics of peptic ulcer disease with a high degree of reliability $(\mathrm{P}<0.1)$ is more common in the presence of a tense environment in the family or at work, stressful situations. Good dynamics, on the contrary, is reliable more often observed against the background of a friendly, calm family and work environment.

Significant $(\mathrm{P}<0.05)$ differences were revealed in the dynamics of the course of peptic ulcer disease in patients who consumed alcohol and who used it systematically: in the latter, unsatisfactory dynamics was recorded more often. No significant difference was found in the 
development of the disease in nonsmokers and smokers, as well as in those who did not use nasvay and use it.

The study of the quality of nutrition of patients confirmed the negative effect of frequent consumption of hot spices, flour food, irregular intake and small amounts of food of food, a lack of fruits and vegetables. We used a scale for scoring risk factors for the onset and development of peptic ulcer disease by the nature of nutrition. Depending on the strength of the influence of each factor, they received an assessment with the corresponding number of points (the stronger the influence, the more points) The scale is divided into 4 groups: no risk - zero points; I degree of risk - 0.5 -3.0; II degree of risk 3.5-6.0; III degree of risk 6.5-10.0 points. Study the dynamics of the disease in accordance with these groupings. In patients who did not have risk factors, unsatisfactory dynamics was noted in $26.4 \%$ of cases. With an increase in the degree of risk, the proportion of such patients increased, reaching $53.9 \%$ in grade III. In all cases, the differences in indicators in the groups who ate rationally and those who violated the nutritional norms were significant $(\mathrm{P}<0.05)$.

There was some difference in the frequency of peptic ulcer exacerbations depending on the season of the year. In summer it was $21.1 \%$, in autumn $28.6 \%(\mathrm{P}<0.05)$. In winter and spring, the indicators were almost the same $(26.1 \%$ and $24.2 \%)$. Determination of the seasonality index showed that it ranges from $86.0 \%$ to $118.8 \%$.

According to our data, there are links between hereditary predisposition and the severity of the clinical course of the disease, in patients with hereditary predisposition the disease is difficult.

The study of the dynamics of the course of peptic ulcer disease, depending on the presence of a hereditary predisposition, showed that the unsatisfactory dynamics is 4 times higher in patients with hereditary diseases in relatives $(18.7 \%, 4.6 \%$, respectively).

Reliable results were obtained by good dynamics in the first group of patients, 1.3 times lower than in the second ( $40.0 \%$ and $52.8 \%$, respectively). However, it should also be noted that out of $19.8 \%$ of cases of patients indicating peptic ulcer disease in their relatives, $13.2 \%$ of patients showed only one relative. In the rest ( $6.6 \%$ of cases), 2 or more relatives were named. The study showed that the combined effect of various unfavorable social and hygienic factors significantly reduces the frequency of good dynamics of gastric ulcer and duodenal ulcer.

The table 2 presents results of analysis of the influence of different factors on the dynamics of the course of gastric ulcer and duodenal ulcer.

Table 2. Analysis of variance (anova) results. Dynamics of the course of gastric ulcer and duodenal ulcer

\begin{tabular}{|l|c|c|c|c|}
\hline \multicolumn{1}{|c|}{ Causes } & F-calculated & F-tabular & Risk & $\begin{array}{c}\text { Power of } \\
\text { influence \% }\end{array}$ \\
\hline Surgical intervention & 368.3 & 4.66 & 0.1 & 45.1 \\
\hline $\begin{array}{l}\text { Including the planned } \\
\text { implementation of surgical } \\
\text { intervention }\end{array}$ & 227.7 & 4.71 & 0.1 & 67.2 \\
\hline Dispensary observation & 23.8 & 4.66 & 0.1 & 7.9 \\
\hline Stage treatment & 23.3 & 4.66 & 0.1 & 7.4 \\
\hline $\begin{array}{l}\text { Clinical examination } \\
\text { + staged treatment } \\
\text { + surgery }\end{array}$ & 236.9 & 4.75 & 0.1 & 74.6 \\
\hline Material and housing conditions & 13.4 & 4.66 & 0.1 & 6.6 \\
\hline Working conditions & 27.3 & 4.62 & 0.1 & 4.5 \\
\hline Feeding & 40.1 & 4.66 & 0.1 & 8.5 \\
\hline Psychological factor & 13.9 & 4.66 & 0.1 & 6.5 \\
\hline
\end{tabular}


The analysis of the dynamics of gastric ulcer and duodenal ulcer with the calculation of a statistical assessment of the reliability is quite convincing and made it possible with maximum reliability $(\mathrm{P}<0.01)$ to conclude that the dynamics of the disease is most strongly influenced (in the complicated form of the disease) by surgical treatment $(45,1 \%)$. In cases when it is carried out in a planned manner, the strength of the impact increases (up to 67.2\%). The effect of clinical examination of patients with gastric ulcer and duodenal ulcer was estimated at $7.9 \%$. This percentage will turn out to be much higher if it is possible to improve the quality of clinical examination, to more clearly organize preventive and health-improving measures.

It is interesting to note that in patients who were under dispensary observation, received full staged treatment, underwent surgery, the power of influence on the dynamics of the disease increased to $74.6 \%$, which indicates the great importance of the complexity of diagnostic, therapeutic and prophylactic effects.

Among the rest, the nutritional factor has the most pronounced effect (8.5). The effect of other factors is approximately the same (material and housing conditions $6.6 \%$; psychological factor $-6.5 \%$ and working conditions $-4.5 \%$ ).

As a result of the study we can draw the following conclusions:

1. Not all patients undergo complete staged treatment (24.3\%). It is necessary to improve the continuity in the work of the polyclinic, hospital, sanatorium in the examination and treatment of these patients.

2. Among the social, hygienic and biological factors, the most pronounced influence is exerted by the nutritional factor $(8.5 \%)$. The effect of other factors is approximately the same (material and housing conditions - 6.6\%; the psychological factor - $6.5 \%$ and working conditions $-4.5 \%$ )

3. The results of the analysis of variance show that when therapeutic and prophylactic measures are taken in a complex manner, the resulting effect increases much.

\section{References}

1. A.A. Abdurakhmanov, Social - hygienic study of the incidence of gastic ulcer and duodenal ulcer. In accordance with the materials of Tashkent city: Thesis of the candidate of medical sciences (Moscow, 1978)

2. O.N.Minushkin, Peptic ulcer (Medicine, Moscow, 1995)

3. I.V.Kopanitsa, Medical - social aspects of the incidence of gastic ulcer and duodenal ulcer in metallurgical production workers and ways of its prevention. Thesis of the candidate of medical sciences (Moscow, 2005)

4. K. Nagashima, K.Tominaga, K.Fukushi, et al, JGH Open, 2 (6), 255-61 (2018)

5. V.T.Ivashkin al., Rus. J. of Gastroenterology, Hepatology, and Coloproctology 30(1), 4970 (2020)

6. G.I. Burchinsky, V.E.Kushnir, Peptic ulcer (Health, Kyiv,1973)

7. A.A.Kalmykov, Complex Social-hygienic examination of men of working age suffering from chronic diseases.(Coronary artery disease, peptic ulcer and diabetes): thesis of the candidate of medical sciences (1987)

8. L.V.Gabbasova et al., Duodenal ulcer in young people (Consulting company Ucom, Tambov, 2017)

9. B.Scally, J.R.Emberson, E.Spata, et al., Lancet Gastroenterol Hepatol. 3(4), 231 (2018)- 